\title{
Conservación de la biodiversidad en Chile, ¿legalmente suficiente? La necesidad de cartografiar la ley antes de decidir
}

\author{
Biodiversity conservation in Chile, legally enough? The need for mapping \\ the law before deciding
}

PATRICIO F. PELLET ${ }^{1 *}$, EDUARDO UGARTE ${ }^{2}$, ENZO M. OSORIO ${ }^{3} \&$ FABIOLA D. HERRERA ${ }^{4}$

\author{
${ }^{1}$ Centro EULA-Chile, Universidad de Concepción, Casilla 160-C, Concepción, Chile \\ ${ }^{2}$ Departamento de Botánica, Universidad de Concepción, Casilla 160-C, Concepción, Chile \\ ${ }^{3}$ Centro de Formación Técnica Diego Portales, Concepción, Chile \\ ${ }^{4}$ INACAP, Coyhaique, Chile \\ *Autor para correspondencia: e-mail: ppellet@mail.com
}

\begin{abstract}
RESUMEN
El 99,8\% del territorio donde se sustenta la biodiversidad es rural y ha estado tradicionalmente regulado por legislación dispersa, sectorial e inorgánica. La legislación moderna, más holística, como la Ley de Bases Generales del Medio Ambiente adolece de imperfecciones relacionadas con la vigencia, la interpretación y, sobre todo, el que la ley se haga cumplir. En este trabajo argumentamos que la aplicación de modelos tomados de la literatura ecológica buscando apoyar la biología de conservación puede ser complementada fuertemente si es acompañada de una medición de la superficie territorial (cantidad y distribución en el espacio) efectivamente afectada por la legislación vigente de protección ambiental. Nuestro trabajo intenta dar respuesta a la pregunta ¿cuánto es lo que efectivamente, en superficie, queda protegido si se hace cumplir la ley? Para esto hemos expresado cartográficamente textos legales relacionados con el bosque nativo, analizamos la complejidad y los efectos de su aplicación y demostramos que basta hacer cumplir la ley para asegurar un mínimo en que, además de aumentar la superficie protegida, aumenta la conectividad y cambian los patrones de fragmentación. La metodología muestra claras ventajas relacionadas con su aplicación para el monitoreo, planificación y control de efectividad de programas sociales.
\end{abstract}

Palabras clave: biodiversidad, bosque nativo, legislación ambiental, Chile.

\begin{abstract}
About $99.8 \%$ of the land sustaining biodiversity in Chile is rural and regulated by legislation, which has been qualified as disperse, too specific or inorganic. Even though modern legislation like (Chilean Law of Environmental Basis) tends to be more holistic in nature, serious imperfections connected with applicability, interpretation and, mainly enforcement still prevails. We argue here that any search for, or application of, ecological models as a support for conservation biology could be strongly complemented by a measurement of the land surface (amount and spatial distribution) effectively affected by present environmental protection legislation. Our study attempts to answer to the question of how much land will be effectively under protection if law is enforced. To answer this question we designed and tested a methodology to express, in cartographic form, legal dispositions related with Chilean native forest protection. We analyzed its complexity and the effects of its application. We show that it is enough to enforce the law to get to assure a minimum of land, which in addition of increasing the currently protected are also increases connectivity while changing fragmentation patterns. Our SIG based methodology has advantages in terms of its application to environmental monitoring, planning and control of social initiatives.
\end{abstract}

Key words: biodiversity, native forest, environmental legislation, Chile.

\section{INTRODUCCIÓN}

Para la conservación biológica, como ciencia aplicada (Meffe \& Carroll 1994), preguntas acerca de filtros gruesos o finos (Simonetti \&
Armesto 1991), representatividad de las redes de áreas protegidas o si ellas satisfacen o no áreas mínimas viables (Soule 1987), o dinámicas (Pickett 1978), adquieren mayor validez si se cuantifica el territorio efectivamente afecta- 
do (superficie en hectáreas) por la legislación. De esta forma, se puede dar respuesta, en escenarios reales, a las preguntas que plantea la biología de la conservación. Resulta obvio que no podemos pretender habitar un territorio bajo disposiciones legales que, en la práctica, no estamos dispuestos a respetar (los ciudadanos) ni a hacer cumplir (la autoridad). En este trabajo argumentamos que los esfuerzos de conservación de la biodiversidad en Chile pueden ser complementados, incorporando los efectos reales que la aplicación de la legislación vigente tiene, en términos de superficie del territorio que será afectada o estará dedicada a la conservación biológica. En cierta forma la nueva ley de bosque nativo busca hacerlo cuando pretende conciliar el rol público y privado que debe tener el bosque nativo buscando el uso sustentable (Ormazábal 1993).

Por otro lado, los espacios rurales $(99,8 \%$ del país es rural y solo $0,2 \%-151.325,12$ ha- es urbano o industrial), es decir, la casi totalidad de los ecosistemas en que se sustenta la biodiversidad en Chile y en la región del Biobío (solo 0,7 \% -24.915,4 ha- es urbano o industrial) no han sido incorporados en esquemas de planificación integral (CONAF-CONAMA 1999a, 1999b).

Históricamente, al igual que en el ámbito internacional (UICN 1980), la legislación ambiental en Chile ha sido fragmentaria e inorgánica y ha respondido a necesidades sectoriales y emergencias; aunque de mucho mayor gravedad es la no aplicación de leyes y reglamentos (UICN 1980, Gallardo 1985, Castillo 1994, Flores 1997).

La legislación ambiental chilena muestra, sin embargo, una clara evolución desde normas sectoriales dispersas a otras más globales (Castillo 1994) como la Ley de Bosques, el Decreto Ley № $701^{1}$ y la Ley de Bases del Medio Ambiente (№ 19.300) que ha sido concebida con una clara perspectiva global, holística, para enfrentar la conservación del ambiente. Persiste, sin embargo, la necesidad de profundizar en el análisis e interpretación de las disposiciones (Castillo 1994), en particular de aquellas orientadas a la protección y conservación de la diversidad biológica.

Gallardo (1985, 1989), por ejemplo, señala que la legislación sobre bosque nativo en Chile

\footnotetext{
${ }^{1}$ Diario Oficial de Chile, 28 de octubre de 1974.
}

es suficiente para asegurar un equilibrio "entre las normas de protección (cuidado) y las de conservación (aprovechamiento racional y sostenido)" (Gallardo 1989), aunque detecta "dispersión e incoherencia" y un "cierto grado de anacronismo" en estas mismas normas (Gallardo 1985). Además, el mismo autor plantea que el artículo quinto de la Ley de Bosques ${ }^{2}$ y los reglamentos que se refieren a especies determinadas, han quedado obsoletos con la promulgación del reglamento técnico del Decreto Ley № 701, por lo que se hace necesario revisar la legislación para derogar disposiciones, actualizar las que no han sido efectivas y dar organicidad y flexibilidad al tratamiento de la flora y vegetación (Gallardo 1985). Por otro lado, Husch (1994) opina que aunque existe un sistema de control legal adecuado para la protección del bosque nativo, este no se aplica simplemente porque CONAF carece del presupuesto y personal adecuados. Además, es necesario destacar que el artículo 39 de la Ley № $18.362^{3}$, que crea el SNASPE, establece que ella no puede entrar en vigencia, en tanto no lo haga la Ley № $18.348^{4}$, que crea la Corporación Nacional Forestal y de Protección de Recursos Naturales Renovables, lo que tampoco ha sucedido.

En general, las opiniones sobre la legislación ambiental coinciden en que la discusión jurídica ha sido pobre (Castillo 1994), que no existe un cuerpo legal definido sobre la protección de la diversidad biológica (Valenzuela 1999), que la dispersión normativa de las áreas protegidas atenta contra los mismos objetivos de su creación (Flores 1997), que la legislación ambiental "además de abundante en número y escasa en calidad, es dispersa, generalmente añeja y no obedece a un ordenamiento orgánico"5 (Ortiz 1990) y muchas veces se desconoce el alcance de su aplicación y existe incertidumbre respecto de su vigencia (CONAMA 1992).

La situación antes descrita conduce al planteamiento de variadas interrogantes como: ¿Es suficiente la legislación existente para asegurar la conservación de la biodiversidad en Chile?, ¿es posible la conservación de un ecosistema o de algún otro nivel de organización biológica

\footnotetext{
${ }^{2}$ Diario Oficial de Chile, 31 de julio de 1931.

${ }^{3}$ Diario Oficial de Chile, 27 de diciembre de 1984.

${ }^{4}$ Diario Oficial de Chile, 19 de octubre de 1984.

5 ORTIZ S (1990) La actividad forestal y su regulación ambiental. Seminario CORMA sobre "Legislación forestal y su dimensión en el derecho ambiental". Concepción, Chile, noviembre 1990.
} 
utilizando solo la legislación ambiental?, ¿de qué modo se puede evaluar el efecto real que una determinada disposición legal tiene sobre la conservación biológica, en cuanto a la superficie de territorio afectada por tal disposición?

Buscando dar una respuesta a esta última pregunta, como objetivo en este trabajo nos hemos propuesto evaluar el efecto de la legislación ambiental vigente sobre la conservación del bosque nativo, diseñando una metodología que permita cuantificar, en términos de superficie territorial (hectáreas), los efectos de las disposiciones legales vigentes específicas para el bosque nativo. Hemos definido dos premisas para el trabajo: (1) que la metodología pueda ser conciliada con relativa facilidad con los instrumentos de planificación existentes, y (2) debe estar basada en información con real significado para la conservación biológica.

Hemos seleccionado como área de estudio la hoya hidrográfica del lago Lleu-Lleu, en la zona costera de la Octava Región, por sus características que representan ventajas comparativas: constituye un ecosistema claramente identificable morfológicamente, en su hoya concurren el uso agrícola tradicional con el forestal de más reciente desarrollo, a pesar de la presión de uso sobre la hoya las aguas del lago conservan su carácter oligotrófico generando controversia acerca de su uso en acuicultura o en turismo y, finalmente, ha sido objeto de conflictos y demandas por la propiedad de la tierra por parte de comunidades mapuches.

\section{MATERIALES Y MÉTODOS}

\section{Primera fase: preparación base de datos del sistema natural}

Se preparó una carta base para la cuenca hidrográfica del lago Lleu-Lleu a partir de las hojas Lleu-Lleu, Purén, Tirúa y Pellahuén del Instituto Geográfico Militar (IGM), digitalizadas a escala 1:50.000; incluye cursos y cuerpos de agua, redes viales, asentamientos urbanos y curvas topográficas.

La cubierta de bosque nativo se obtuvo a partir de los resultados contenidos en el Catastro y Evaluación de los Recursos Vegetacionales Nativos de Chile (CONAF-CONAMA 1998).

Se utilizaron el Sistema de Información (SIG) ARC INFO volumen 7.21 y ARC VIEW volumen 3.2 para integrar los diversos antecedentes, editar y analizar la base de datos, realizar los cálculos y elaborar las cartas temáticas contenidas en el estudio.

Segunda fase: selección y análisis de normativa legal

Preparación base de datos legal. De revisiones bibliográficas, se preparó una base de datos con la legislación vigente en la temática ambiental, incluyendo normas jurídicas, documentos de análisis, descripción y caracterización de normas así como estudios generados por especialistas.

Identificación y descripción de la legislación relacionada con el bosque nativo. Como resultado de una primera inspección del listado anterior de disposiciones legales, se seleccionaron solo aquellas relacionadas con la vegetación y flora. Junto con simplificar el trabajo, esta selección y las posteriores se orientaron a satisfacer nuestro objetivo de determinar la extensión del territorio protegido asegurando un "mínimo" cumplimiento de la legislación vigente.

En un segundo "filtrado" de disposiciones legales, se retuvieron solo aquellas normas que se orientan a proteger y conservar el bosque nativo en la cuenca del lago Lleu-lleu. Esta decisión se justifica en que la vegetación original del área corresponde a bosque nativo según E. Ugarte (comunicación personal) y en la actualidad, subsisten remanentes fragmentados y concentrados en el tercio superior de la cuenca. Por otro lado, conservar la biodiversidad en el área equivale, en la práctica, a conservar la cubierta de bosque nativo aun sin considerar la composición o riqueza específica ni las comunidades que pudiera eventualmente llegar a reconocerse.

Este grupo de normas se ordenó jerárquicamente siguiendo a Gallardo $(1985,1989)$.

Análisis de la legislación ambiental seleccionada. La legislación seleccionada se analizó usando como escenario una posible intervención (conservación, explotación, manejo) del bosque nativo presente en la cuenca del lago Lleu-Lleu.

Tercera fase: preparación de cartas temáticas y de sintesis

Preparación de cartas temáticas para normativas jurídicas. Se expresó cartográficamente la legis- 
lación, analizada en el punto anterior, siguiendo las recomendaciones de King (1993), esto es, se obtuvo una carta temática para cada una de las normas jurídicas identificadas, utilizando para ello criterios planimétricos obtenidos de los atributos específicos que la legislación define, tales como: presencia de bosque nativo, localización de manantiales, porcentajes de pendientes o distancias mínimas con respecto a algún elemento en particular (cerros, ríos). Se utilizó el SIG ARC INFO para obtener una carta temática de cada una de las normas jurídicas identificadas.

Como fundamento para la interpretación de la ley, se siguieron los artículos 19 al 24 contenidos en el número cuatro, Título Preliminar, del Código Civil chileno.

Preparación de carta de síntesis. Se generó una carta de síntesis por superposición de las cartas temáticas normativas. En ella se pueden visualizar todos los espacios del territorio que poseen bosque nativo y además están protegidos desde la perspectiva legal.

\section{RESULTADOS}

\section{Área de estudio}

La cuenca del lago Lleu-Lleu se ubica en la zona centro-sur de Chile, al sur-oeste de la Octava Región, entre los $38^{\circ} 02^{\prime}$ y $38^{\circ} 18^{\prime}$ S, entre $\operatorname{los} 73^{\circ} 07^{\prime}$ y $73^{\circ} 26^{\prime} \mathrm{O}$ y ocupa una superficie de $57.880,98$ ha $(1,6 \%$ de la superficie regional) (Fig. 1).

Posee $8.722,99$ ha de bosque nativo $(15,07$ $\%$ del total), que puede ser clasificado, desde el punto de vista de su composición, en dos categorías o tipos forestales (Fig. 2): el tipo robleraulí-coigüe $(7.399,87$ ha) y el tipo siempreverde $(1.320,77 \mathrm{ha})$.

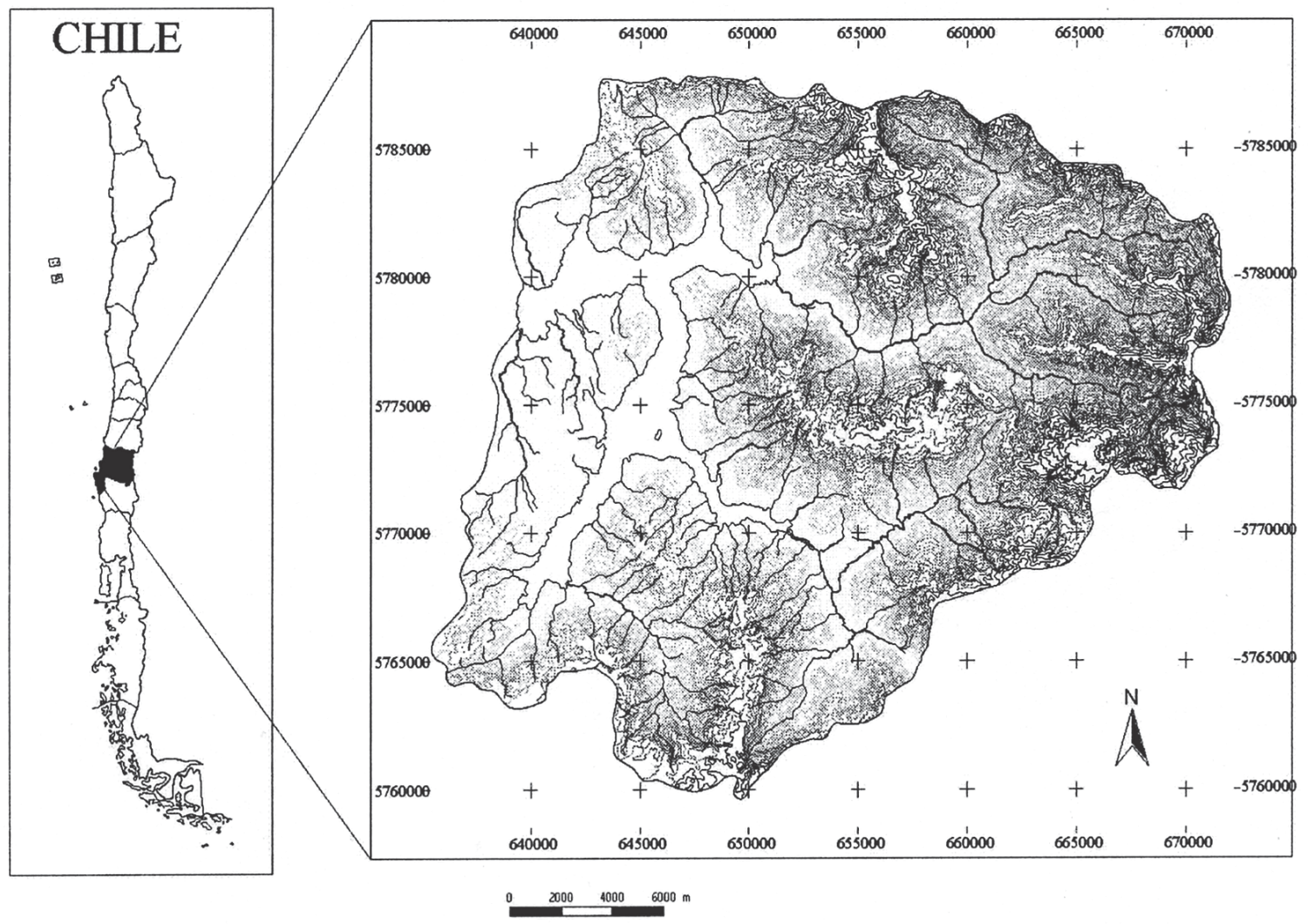

Fig. 1: Área de estudio. Cuenca hidrográfica del lago Lleu-Lleu, Octava Región, Chile (coordenadas UTM).

Study area. Lago Lleu-Lleu basin, Octava Región, Chile (UTM coordinates). 


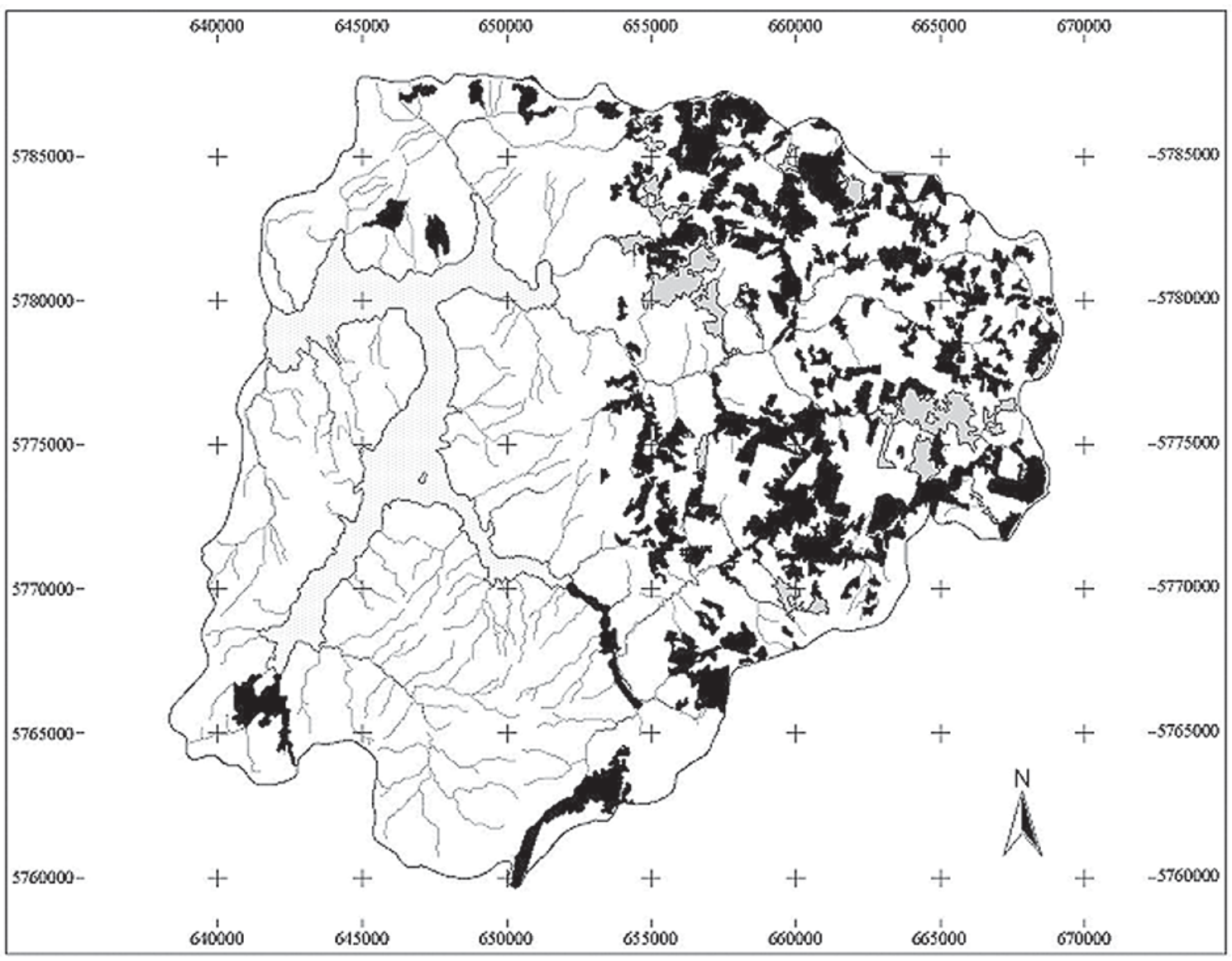

Leyenda

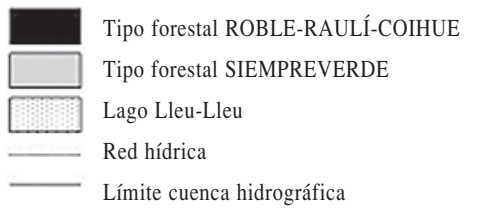

Fig. 2: Bosque nativo: tipos forestales roble-raulí-coigüe y siempreverde (coordenadas UTM).

Native forest: forest types roble-raulí-coigüe and siempreverde (UTM coordinates).

Recopilación de antecedentes: selección y análisis de la legislación

Se recopiló más de 750 textos legales que se orientan a la conservación del ambiente. Entre las fuentes destaca la completa recopilación preparada por la Comisión Nacional del Medio ambiente (CONAMA 1992, 1993). Con posterioridad la Ley de Bases Generales del Medio Ambiente y su reglamento (1994 y
1997 respectivamente) y una serie de disposiciones sobre calidad del aire y agua. De la base de datos, se extrajo la normativa referente a la biodiversidad, luego a la flora y vegetación y, finalmente, la referida al bosque nativo. En la Tabla 1 se entrega una síntesis de la legislación ambiental que es aplicable en la cuenca del lago Lleu-Lleu y que, además, se orienta a la protección del bosque nativo. 


\section{TABLA 1}

Legislación ambiental aplicable en la cuenca hidrográfica del lago Lleu-Lleu, referida a la protección del bosque nativo $(\mathrm{DO}=$ Diario Oficial; $\mathrm{DL}=$ Decreto Ley; DS $=$ Decreto Supremo)

Environmental legislation as applied in Lleu-Lleu lake basin and referred to native forest protection $(\mathrm{DO}=$ Official Law Periodical; $\mathrm{DL}=$ Law Decree, $\mathrm{DS}=$ Supreme Decree $)$

\begin{tabular}{|c|c|}
\hline Categoría & Descripción \\
\hline \multicolumn{2}{|l|}{ Norma constitucional } \\
\hline Artículo 19 , № 8 & Derecho a vivir en un medio ambiente libre de contaminación \\
\hline Artículo 19 , № 24 & Derecho de propiedad \\
\hline Artículo 20 , inciso $2^{\circ}$ & Consagra el recurso de protección \\
\hline Artículo 21 , inciso $1^{\mathrm{o}}$ & Derecho a desarrollar cualquiera actividad económica \\
\hline \multicolumn{2}{|l|}{ Norma legal } \\
\hline Ley № 19.300 & Ley de Bases Generales del Medio Ambiente \\
\hline DL № 701 & Sobre fomento forestal \\
\hline Ley № 17.288 & Sobre monumentos nacionales \\
\hline Ley № 11.402 & Sobre las obras de defensa y regularización de las riberas y cauces de los ríos, lagunas y esteros \\
\hline Ley № 18.378 & Sobre distritos de conservación de suelos, bosques y aguas; y conservación de la riqueza turística \\
\hline DS № 141 & $\begin{array}{l}\text { Aprueba convención sobre el comercio internacional de especies amenazadas de fauna y flora } \\
\text { silvestres (CITES) }\end{array}$ \\
\hline DL No 3.485 & $\begin{array}{l}\text { Aprueba convención relativa a las zonas de importancia internacional, especialmente como hábitat } \\
\text { de las aves acuáticas, firmada en Ramsar, Irán, el } 2 \text { de febrero de } 1971 \text {. }\end{array}$ \\
\hline \multicolumn{2}{|l|}{ Norma reglamentaria } \\
\hline DS № 30 & Reglamento del sistema de evaluación de impacto ambiental \\
\hline DS № 193 & Reglamento general DL 701 \\
\hline DS № 259 & Reglamento técnico del DL 701 de 1974 \\
\hline DS № 192 & Reglamento para el pago de las bonificaciones forestales \\
\hline DS № 1.341 & $\begin{array}{l}\text { Reglamento que establece normas contables aplicables a los contribuyentes que realizan activida- } \\
\text { des forestales de conformidad al DL } 701 \text { de } 1974\end{array}$ \\
\hline DS № 4.363 & Ley de Bosques \\
\hline DS № 531 & $\begin{array}{l}\text { Convención de Washington. Dispone que se cumpla y lleve a cabo la "Convención para la protec- } \\
\text { ción de la flora, la fauna y las bellezas escénicas naturales de América", firmada en Washington el } \\
12 \text { de octubre de } 1940\end{array}$ \\
\hline DS № 771 & $\begin{array}{l}\text { Promulga la convención sobre zonas húmedas de importancia internacional especialmente como } \\
\text { hábitat de las aves acuáticas, suscrito en Irán el } 2 \text { de febrero de } 1971\end{array}$ \\
\hline DS № 971 & $\begin{array}{l}\text { Protocolo para enmendar la convención sobre zonas húmedas de importancia internacional espe- } \\
\text { cialmente como hábitat de las aves acuáticas }\end{array}$ \\
\hline DS № 2.374 & Aprueba el reglamento para la explotación de bosques existentes en las cuencas hidrográficas. \\
\hline
\end{tabular}

\section{Sobre la interpretación de la ley}

La interpretación de las normas jurídicas resultó de gran relevancia para la expresión territorial de la conservación del bosque nativo. Esto queda de manifiesto en los siguientes tres casos que ilustran tres situaciones diferentes de interpretación:

Primer caso: el Decreto Supremo № $2.374^{6}$ sobre bosques en hoyas hidrográficas, es una norma que, aun cuando ofrece grandes posibili-

\footnotetext{
${ }^{6}$ Diario Oficial de Chile, 24 de noviembre de 1937.
}

dades para la conservación del bosque nativo, no pudo ser aplicada en este trabajo debido a conflictos respecto de su interpretación.

La ley se refiere a la explotación de bosques existentes en cuencas hidrográficas declaradas forestales. Establece que los individuos objeto de corta, de cualquier especie, deberán tener un diámetro mínimo de $20 \mathrm{~cm}$. Además, la corta o explotación de estos bosques no se podrá realizar en toda la extensión de una sola vez, sino que deberá hacerse en paños progresivos. Adicionalmente, en su artículo 4ํㅗa seña que: "En 
todas aquellas situaciones en que el terreno sea de excesiva pendiente, o en que la naturaleza de él sea muy desagregable se impedirá en absoluto la explotación forestal, por lo menos en una zona no menor de $200 \mathrm{~m}$ a un lado y otro del talweg ${ }^{7}$. Esta distancia se medirá sobre la cota de aguas máximas, en la zona de los talweg en que se hayan construido embalses".

El problema surge cuando se trata de identificar cuáles son las "cuencas forestales". La ley, a través de decretos supremos, identifica expresamente las cuencas que deberán tratarse como forestales; la cuenca del lago Lleu-Lleu no está incluida. Sin embargo, en opinión de Ortiz (1986), este reglamento se orienta a evitar la destrucción del equilibrio hidrológico-forestal, a través de un sistema de explotación de bosques insertos en una cuenca y establecidos sobre terrenos declarados forestales. Por lo tanto, señala, deben incluirse los terrenos declarados como tales por la Ley de Bosques así como aquellos calificados de aptitud preferentemente forestal por el Decreto Ley № 701. En consecuencia, según Ortiz (1986), esta ley sería aplicable en todos aquellos "terrenos que fueron declarados forestales en la Ley de Bosques y a los que han sido y serán calificados en el Decreto Ley 701". Bajo este predicamento la cuenca del Lleu-Lleu debería considerarse como una "cuenca forestal". En la práctica esta ley no es aplicada.

Segundo caso: La expresión cartográfica de la legislación fue posible porque algunas variables están claramente definidas en las normas que las expresan, por ejemplo, el ancho de las franjas de protección. Sin embargo, en la práctica, otras quedan sujetas a la libre interpretación de quien las aplica.

El artículo 50 de la Ley de Bosques ${ }^{8}$, en su número 1, prohíbe: "La corta de árboles y arbustos nativos situados a menos de 400 metros sobre los manantiales que nazcan en los cerros...)", por lo que, desde el punto de vista de la ciencia ambiental, se debería recurrir a las definiciones técnicas de la geomorfología; sin embargo, el Código Civil chileno establece en su artículo 20 que: "las palabras de la ley se entenderán en su sentido natural y obvio, según el uso general de las mismas palabras (...)". Esto significa que para aplicar la ley menciona-

\footnotetext{
${ }^{7}$ Línea que une los puntos más bajos de una quebrada.

${ }^{8}$ Ley $^{\circ} 4.363$.
}

da un cerro puede ser definido, simplemente, como una "elevación aislada del terreno".

Tercer caso: el Decreto Ley 701 señala en su artículo № 53 que el tipo forestal araucaria se regirá por el Decreto Supremo № $43^{9}$ que declara Monumento Natural a la araucaria (Araucaria araucana); vulnerable en el listado nacional de especies con problemas de conservación (Benoit 1989). Si se intenta intervenir las poblaciones de aquellas especies que acompañan a la araucaria, por ejemplo de lenga o coigüe, surge un claro problema de interpretación. En efecto, el Reglamento Técnico del Decreto Ley 701 define como tipo forestal a una "agrupación arbórea que crece en un área determinada, caracterizada por las especies predominantes en los estratos superiores del bosque o porque estas tengan una altura mínima dada"10. Claramente se refiere a la comunidad biológica que establece la araucaria, en nuestro caso, y sus especies acompañantes. Sin embargo, el Decreto Supremo № $43^{11}$ declara Monumento Natural a la araucaria en acuerdo con la definición y espíritu de la "Convención para la Protección de la Flora, la Fauna y las Bellezas Escénicas Naturales de América”. Por lo tanto, su carácter de Monumento Natural debe ser entendido de acuerdo con el artículo I, número 3, del Decreto Supremo № 531 ${ }^{12}$, es decir, corresponde a: "las regiones, los objetos o las especies vivas de interés estético o valor histórico o científico, a los cuales se les da protección absoluta. Los monumentos naturales se crean con el fin de conservar un objeto específico o una especie de flora o fauna declarando una región, un objeto o una especie aislada, monumento natural inviolable excepto para realizar investigaciones científicas debidamente autorizadas, o inspecciones gubernamentales".

\section{La legislación actual y la intervención del bos- que nativo}

Usando como base las normas señaladas en la Tabla 1, a continuación se describe la situación del bosque nativo frente a una posible intervención; la Fig. 3 resume las vías legales posibles. Con el mismo esquema se construye su expresión cartográfica.

\footnotetext{
${ }^{9}$ Diario Oficial de Chile, 3 de abril de 1990.

${ }_{10}$ Artículo $1^{\circ}$, letra n, Decreto Supremo $N^{\circ} 193$, Diario

Oficial de Chile, 29 de septiembre de 1998.

${ }^{11}$ Diario Oficial de Chile, 3 de abril de 1990.

${ }^{12}$ Diario Oficial de Chile, 4 de octubre de 1967.
} 


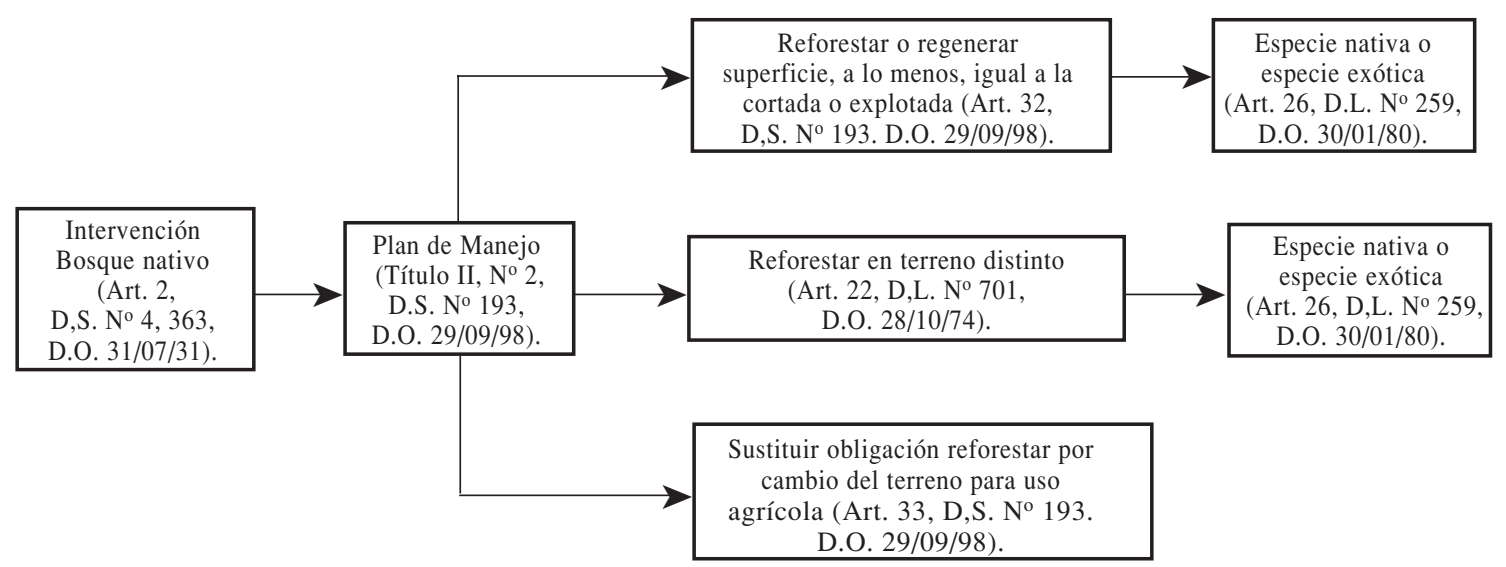

Fig. 3: Posibles caminos o vías legales de intervención del bosque nativo en la cuenca del lago Lleu-Lleu. Se incluyen los artículos y la ley que los contiene (ver explicación en el texto a continuación); DL = Decreto Ley; DS = Decreto Supremo; DO = Diario Oficial; Art = Artículo.

Ways for legal intervention of present native forest in Lleu-Lleu lake basin. Articles and the law that contains them are included (see the text for further explanation); DL = law decree; DS = supreme decree; DO = official law periodical; Art = article.

Como muestra la Fig. 3, cualquier intervención del bosque nativo requiere la aprobación de un Plan de Manejo (PDM) por la CONAF, independientemente de que el terreno sea o no de aptitud forestal ${ }^{13}$.

Lo anterior implica preparar un PDM específico para el sector a intervenir, o adscribirse a un PDM estándar, según especificaciones legales avaladas por la CONAF para especies o tipos forestales específicos ${ }^{14}$. Ellos deben incorporar el programa de corta, explotación y reforestación, junto con una descripción del sitio, los objetivos de manejo, el tratamiento silvicultural, la superficie a intervenir, el tipo forestal y un programa de protección, entre otras 15 .

Dado que en el área de estudio se reconocen dos tipos forestales, es posible utilizar cualquiera de los cuatro métodos de corta o explotación definidos en el Reglamento Técnico del Decreto Ley № 701, cuando se trata de un PDM tradicional (ver Tabla 2).

TABLA 2

Métodos de corta o explotación permitidos para el bosque nativo en la cuenca hidrográfica del lago Lleu-Lleu y los rangos de pendiente donde es posible su utilización (Fuente: CONAF 1994)

Accepted cutting or exploitation methods for native forest in Lleu-Lleu basin and the slope values over which its utilization is possible (Source: CONAF 1994)

\begin{tabular}{|c|c|c|c|c|c|c|}
\hline \multirow{2}{*}{$\begin{array}{l}\text { Método de corta } \\
\text { o explotación }\end{array}$} & \multicolumn{2}{|c|}{ Tipo forestal } & \multicolumn{4}{|c|}{ Pendiente $(\%)$} \\
\hline & Ro-ra-co & Siempreverde & $0-30$ & $30-45$ & $45-60$ & $>60$ \\
\hline Tala rasa & $*$ & & $*$ & $(*)$ & & \\
\hline Árbol semillero & $*$ & & $*$ & $(*)$ & & \\
\hline De protección & $*$ & $*$ & $*$ & $*$ & $*$ & \\
\hline Selectivo o entresaca & $*$ & $*$ & $*$ & $*$ & $*$ & $*$ \\
\hline
\end{tabular}

Ro-ra-co: roble-raulí-coigüe; $(*)$ con restricciones: solo se permite cortar sectores con una superficie máxima de 20 ha, dejando franjas boscosas de $100 \mathrm{~m}$ entre ellos.

${ }^{13}$ Artículos 2 del Decreto Supremo $N^{\circ} 4.363$ y 21 del Decreto Ley $\mathrm{N}^{\circ} 701$

${ }^{14}$ Artículo $11^{\circ}$, Decreto Supremo $N^{\circ} 193$.

\footnotetext{
$\overline{15}^{15}$ ítulo II, $\mathrm{N}^{\circ}$ 2; de los Planes de Manejo, Decreto Supremo $\mathrm{N}^{\circ} 193$.
} 
Aunque los métodos de corta están claramente definidos, se puede aplicar uno distinto al señalado para un tipo forestal, o variaciones de ellos, o cualquier otra alternativa silvicultural, siempre que se garantice la reposición del bosque y la conservación de los suelos ${ }^{16}$.

Una vez intervenido el bosque nativo, se puede seguir una de tres vías legales disponibles. (1) Existe la obligación de reforestar o regenerar una superficie igual o superior a la cortada o explotada ${ }^{17}$; con un mínimo de 3.000 plantas ha $^{-1}$, de la misma especie, homogéneamente distribuidas e independientemente del método utilizado. (2) No obstante lo anterior, la reforestación puede ser realizada en el mismo lugar o en un terreno distinto ${ }^{18}$. Además, es posible sustituir la especie utilizada para reforestar por otra nativa o exótica. El PDM debe contener los antecedentes, experimentalmente demostrados, de que la especie a emplear está adaptada al lugar y que no se provocará erosión del suelo ${ }^{19}$. (3) Es posible sustituir la obligación de reforestar por un cambio del terreno explotado para fines agrícolas ${ }^{20}$. Sin embargo, las acciones referidas no se permiten cuando existen especies catalogadas En Peligro de Extinción, Vulnerable, Rara o Insuficientemente Conocida ${ }^{21}$.

Junto con las disposiciones anteriores, en el área de estudio se pueden aplicar normas de manejo específicas para cada uno de los tipos forestales identificados.

La primera se refiere a las normas de manejo aplicables a faenas de raleo para el tipo forestal roble-raulí-coigüe (CONAF 1994). En este conjunto de requisitos y normativas las medidas de protección adquieren especial relevancia para este estudio, ya que tienen por objeto "compatibilizar los objetivos de producción maderera con los de protección del medio ambiente" 22 . En este punto se establece que los cursos de agua permanentes contarán con una franja de protección de $30 \mathrm{~m}$ de ancho a cada lado del afluente. Esta faja no podrá ser intervenida, incluso no se permite la caída de árboles desde áreas vecinas que estén siendo intervenidas. Los cursos de agua no permanentes se

\footnotetext{
${ }_{16}$ Artículo $25^{\circ}$, Decreto Supremo $\mathrm{N}^{\circ} 259$.

17 Artículo $32^{\circ}$, Decreto Supremo $N^{\circ} 193$.

${ }^{18}$ Artículo $22^{\circ}$, Decreto Ley $\mathrm{N}^{\circ} 701$.

${ }^{19}$ Artículo $26^{\circ}$, Decreto Supremo $\mathrm{N}^{\circ} 259$.

${ }^{20}$ Artículo $33^{\circ}$, Decreto Supremo $N^{\circ} 193$.

${ }^{21}$ Artículo 42 ${ }^{\circ}$, Decreto Supremo $N^{\circ} 193$.

${ }^{22}$ Letra g, punto 6 "Criterios técnicos a considerar para la ejecución de las faenas de raleo".
}

protegen con una franja de $15 \mathrm{~m}$ de ancho como mínimo en sectores que están siendo intervenidos. También se protege de cualquier intervención las áreas de pendientes iguales o superiores a $60 \%$ por más de $30 \mathrm{~m}$ (Fig. 4).

La segunda se refiere a las normas de manejo aplicables a la corta final en el tipo forestal siempreverde (CONAF 1995). En el documento se señala el ámbito legal de aplicación de estas normas, los bosques a intervenir, su clasificación y descripción. También se indican las medidas de protección necesarias para el desarrollo de estas actividades y, por último, el tipo de formulario a utilizar, la tramitación de estas normas y la forma de fiscalizar su cumplimiento. Las medidas de protección en este caso tienen como objetivo "[...] salvaguardar la integridad de los árboles que queden en pie y de manera muy importante, la regeneración que se ha establecido en las zonas de volteo" (CONAF 1995 , p. 26). Se da especial relevancia a los cursos de agua, donde se establece una franja de protección que será excluida de toda intervención, de acuerdo con los criterios expresados en la Tabla 3. Se incluyen en estas restricciones tanto los cursos de agua permanentes como aquellos no permanentes.

TABLA 3

Restricciones para la corta del tipo forestal siempreverde asociadas a los cursos de agua de la hoya hidrográfica del lago Lleu-Lleu (Fuente: CONAF 1995)

Cutting restrictions valid for evergreen forest type associated with water courses within Lleu-Lleu lake basin (Source: CONAF 1995)

\begin{tabular}{ccc}
\hline Cauce no permanente & Cauce permanente & Pendiente $(\%)$ \\
\hline 10 & 20 & $<30$ \\
15 & 25 & $30-45$ \\
20 & 30 & $>45$ \\
\hline
\end{tabular}

Además de las anteriores, se incluyen otras áreas denominadas "frágiles", donde no se permite la tala, descepado, destrucción, explotación o aprovechamiento de los árboles. Entre ellas, se cuentan las superficies con pendientes superiores a $60 \%$ en trechos superiores a $75 \mathrm{~m}$; los bosques en una franja de $100 \mathrm{~m}$ desde la línea de altas mareas y alrededor de los lagos, y los bosques a una distancia de $15 \mathrm{~m}$ horizontales a cada lado de caminos públicos (Fig. 5). 


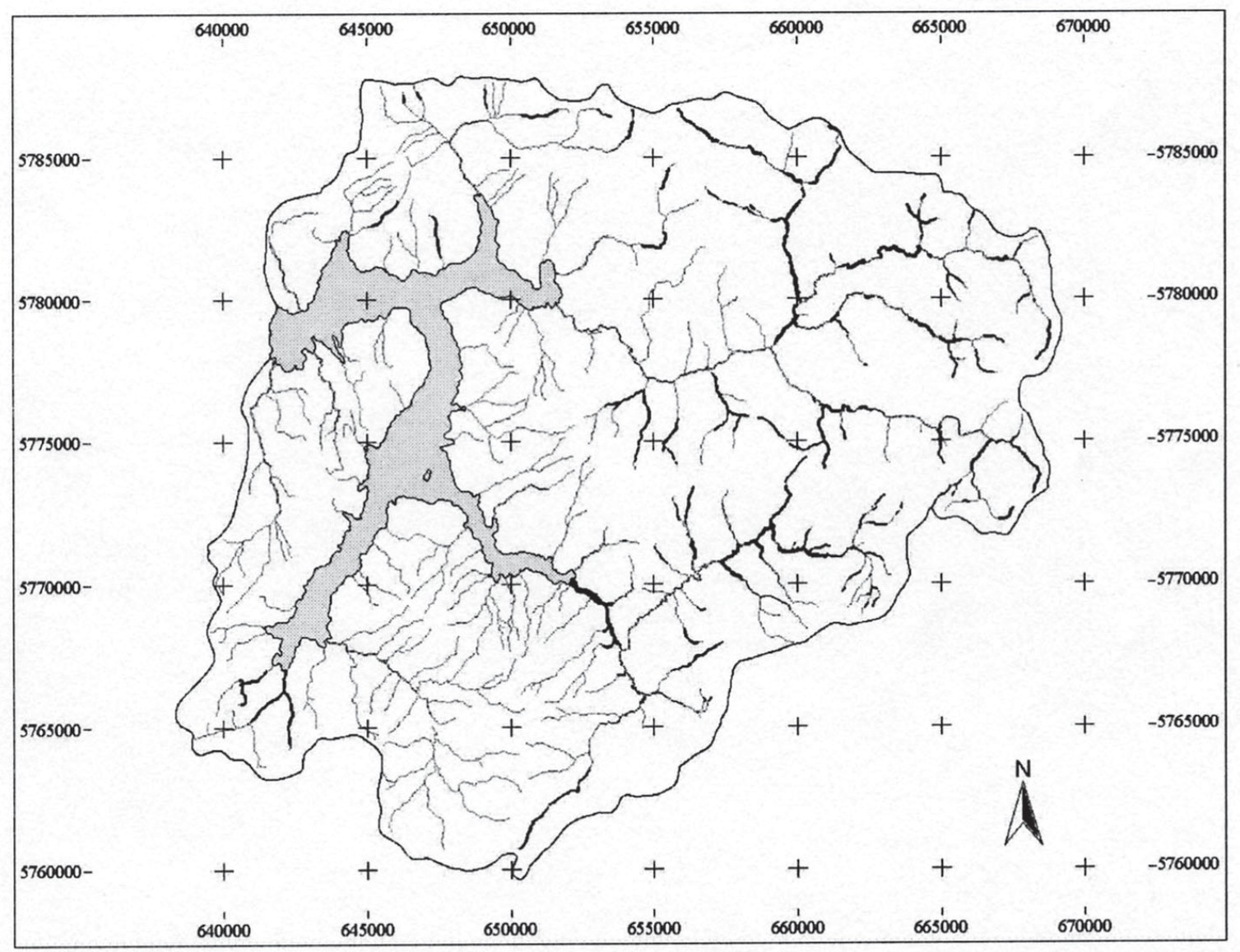

Leyenda

$\begin{array}{ll}\square & \text { Bosque nativo protegido } \\ \square & \text { Lago Lleu-Lleu } \\ \square & \text { Red hídrica } \\ \square \quad \text { Límite cuenca hidrográfica }\end{array}$

Fig. 4: Expresión cartográfica de la norma CONAF para el tipo forestal roble-raulí-coigüe según se aplica a la cuenca del lago Lleu-Lleu (coordenadas UTM).

Cartographic expression of CONAF norm for roble-raulí-coigüe forest type as applied to lago Lleu-Lleu basin (UTM coordinates).

Junto con todo lo anterior, en el área de estudio el tratamiento del bosque nativo exige dar cumplimiento a la Ley № $4.363^{23}$, Ley de Bosques, que en su artículo № 5 prohíbe: “(1) la corta de árboles y arbustos nativos situados a menos de $400 \mathrm{~m}$ sobre los manantiales que nazcan en los cerros y los situados a menos de $200 \mathrm{~m}$ de sus orillas desde el punto en que la vertiente tenga su origen hasta aquel en que llegue al plano; (2) la corta o destrucción del arbolado situado a menos

${ }^{23}$ Diario Oficial de Chile, 31 de julio de 1931. de $200 \mathrm{~m}$ de radio de los manantiales que nazcan en terrenos planos no regados; (3) la corta o explotación de árboles y arbustos nativos situados en pendientes superiores a $45 \%$.

No obstante, se puede cortar en dichos sectores solo por causas justificadas y previa aprobación de plan de manejo en conformidad al Decreto Ley № 701 de 1974”24 (Fig. 6).

${ }^{24}$ Ley 18.959 (Diario Oficial de Chile, 24 de febrero de 1990). Ver artículo 21 de la misma ley que establece las sanciones por su no cumplimiento. 


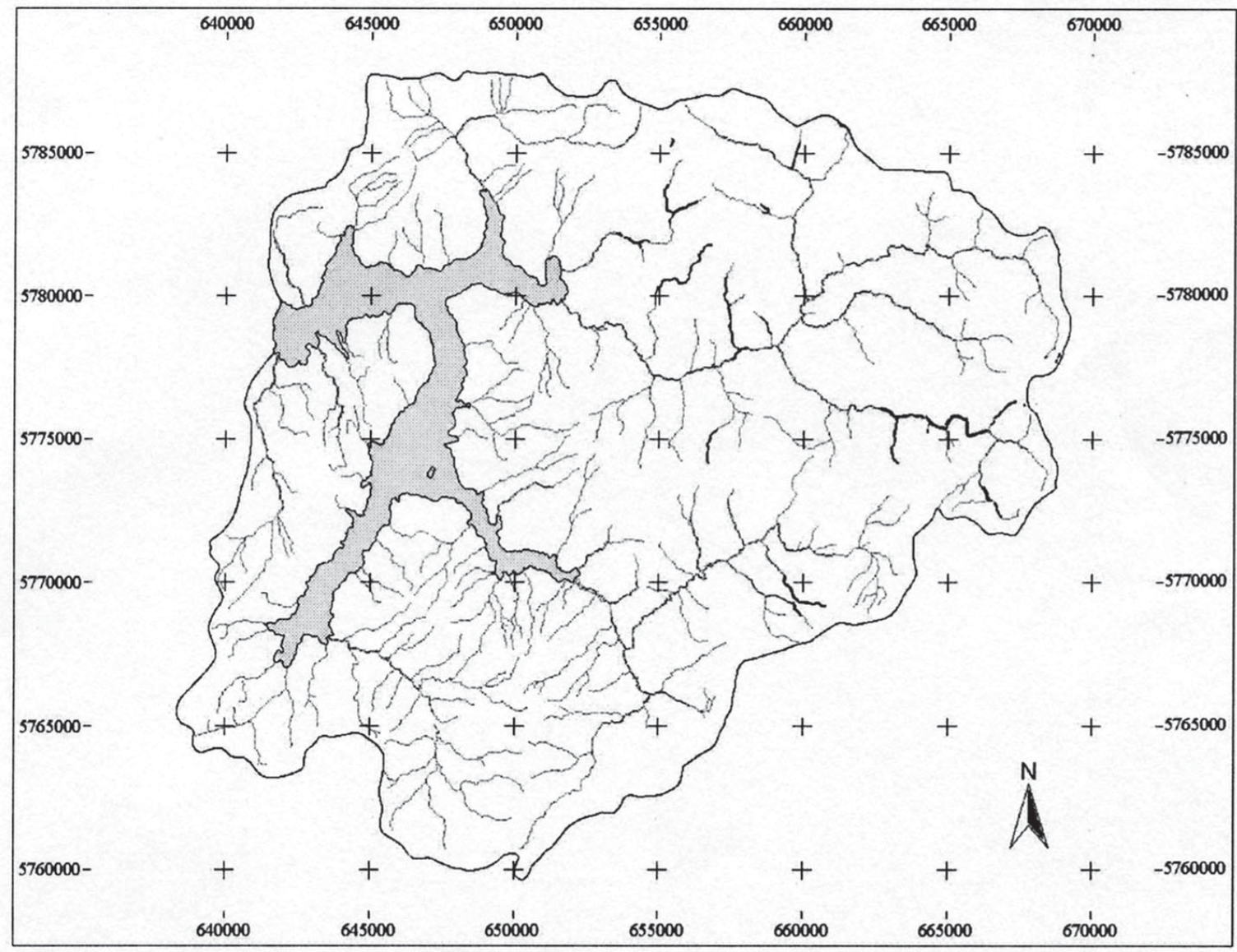

Leyenda

\begin{tabular}{l}
$\square$ \\
$\square$ Lagque nativo protegido \\
$\begin{array}{l}\square \\
\square \\
\square \quad \text { Red hídrica }\end{array}$ \\
\hline$\quad$ Límite cuenca hidrográfica
\end{tabular}

Fig. 5: Expresión cartográfica de la norma CONAF para el tipo forestal siempreverde según se aplica a la cuenca del lago Lleu-Lleu (coordenadas UTM).

Cartographic expression of CONAF norm for evergreen forest type as applied to lago Lleu-Lleu basin (UTM coordinates).

En la práctica, tiene mayor jerarquía legal el Decreto Ley № 701, de manera que estas prohibiciones se entienden incluidas en los planes y normas de manejo que regula $\mathrm{CONAF}^{25}$ para los distintos tipos forestales involucrados (Osvaldo Navra, comunicación personal); además, explícitamente los artículos $1^{\circ}$ y $2^{2}$ de la Ley de Bosques aluden al citado decreto como rector de estas y otras disposiciones.

\footnotetext{
${ }^{25}$ Artículo $11^{\circ}$ (Título I) y artículos del $28^{\circ}$ al $42^{\circ}\left(\mathrm{N}^{\circ} 2\right.$ de los planes de manejo, Título II De las Normas Técnicas) en el Decreto Supremo N ${ }^{\circ} 193$ (Diario Oficial de Chile, 29 de septiembre de 1998).
}

Por otro lado, también es aplicable en el área la Ley № $18.378^{26}$, que se refiere a suelos erosionados o con riesgos de erosión. Según señala, se pueden crear distritos de conservación de suelos, bosques y aguas mediante decreto expedido por el Presidente de la República, a través del Ministerio de Agricultura, previo informe del Servicio Nacional de Turismo. Para tal efecto, si se requiere conservar la riqueza turística, según su artículo $4^{\circ}$, se podrá dictar prohibición de cortar los "árboles situados has-

${ }^{26}$ Diario Oficial de Chile, 29 de diciembre de 1984. 


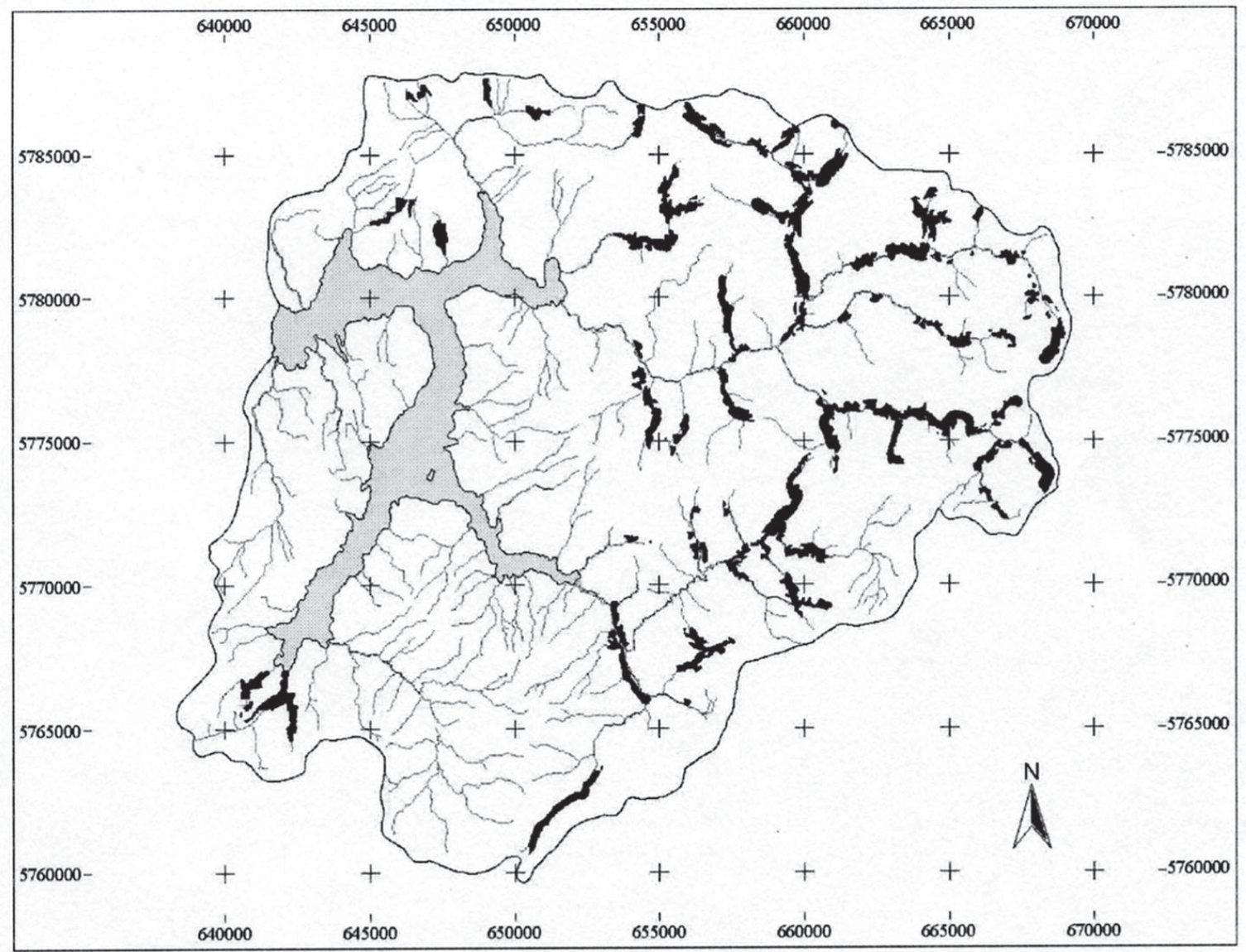

\section{Leyenda}

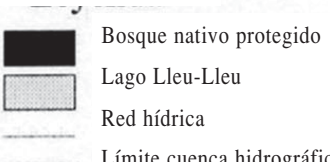

Fig. 6: Expresión cartográfica de la Ley de Bosques según se aplica a la cuenca del lago Lleu-Lleu (coordenadas UTM).

Cartographic expression of Forest Law as applied to lago Lleu-Lleu basin (UTM coordinates).

ta a cien metros $(100 \mathrm{~m})$ de las carreteras públicas y de las orillas de ríos y lagos que sean bienes nacionales de uso público, como también, en quebradas u otras áreas no susceptibles de aprovechamiento agrícola o ganadero". En la Fig. 7 se representa cartográficamente el artículo $4^{\circ}$ de esta ley.

Los siguientes argumentos refuerzan la aplicación de la Ley 18.378 en el área: (a) El reciente desarrollo de un Plan Seccional para el lago Lleu-Lleu (Durán \& Martínez 2000), cuyo diseño e implementación está basado en dos variables consideradas estratégicas para el sector: las aptitudes que ofrece para el turismo y la protec- ción del lago Lleu-Lleu. (b) La promulgación del Decreto Supremo № $60^{27}$, que declara Área de Desarrollo Indígena a la zona del lago LleuLleu. Aquí se señala que, dadas las condiciones climáticas existentes, el área posee altos riesgos de erosión, y que el bosque nativo "ha sido diezmado fuertemente por la actividad silvícola, por especies exógenas como el pino radiata y eucalipto". (c) Las particulares características del área de estudio: notable constancia en las condiciones ambientales, recurrencia de fenómenos geológicos que rejuvenecen el lago y gran poten-

\footnotetext{
${ }^{27}$ Diario Oficial de Chile, 8 de agosto de 1901.
} 


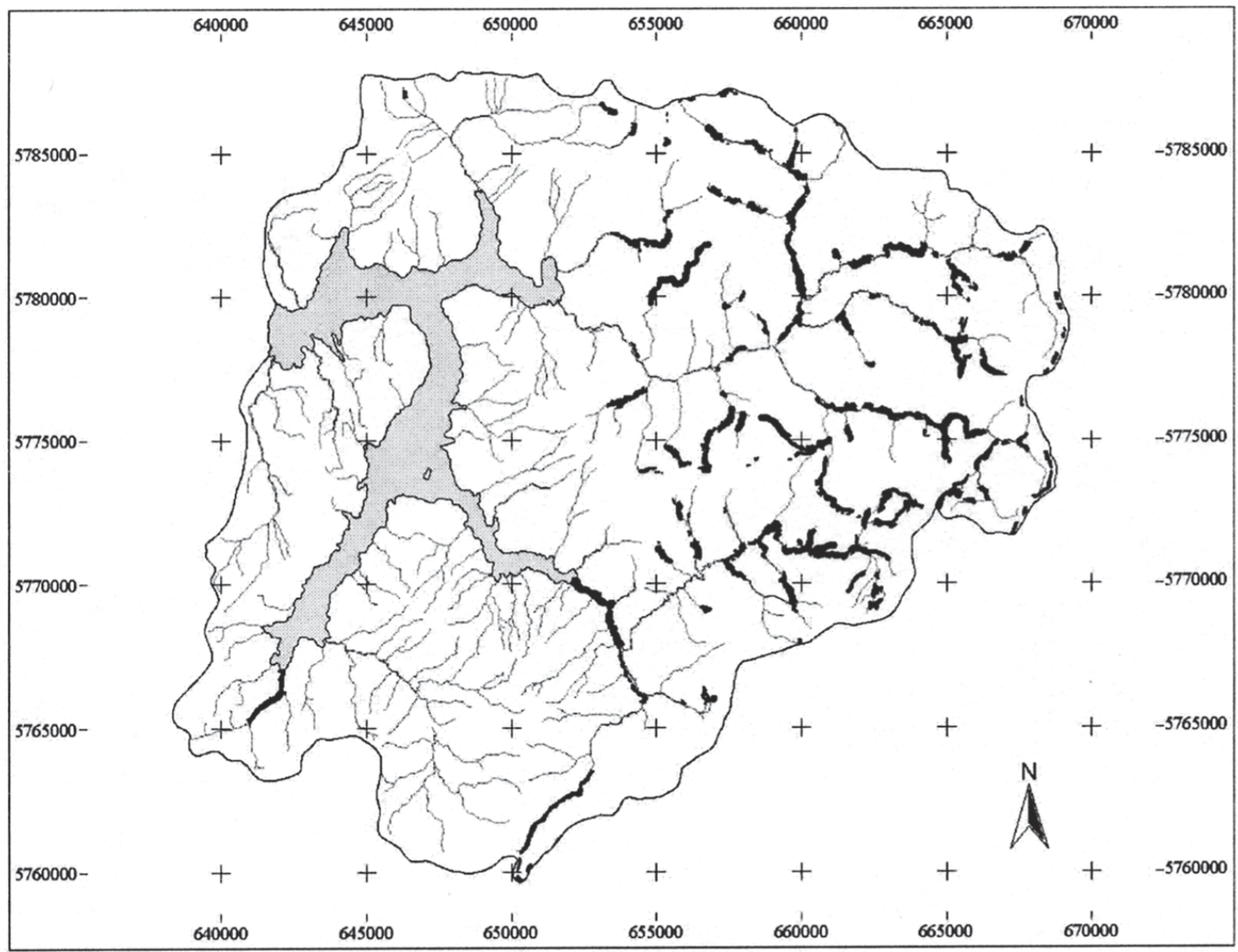

Leyenda
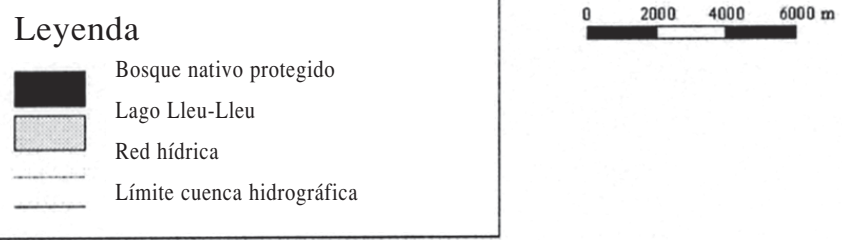

Fig. 7: Expresión cartográfica de la Ley 18.378 en su aplicación en la cuenca del lago Lleu-Lleu (coordenadas UTM).

Cartographic expression of Law 18.378 as applied to Lleu-Lleu lake basin (UTM coordinates).

cial turístico (Mardones 1999), estado oligotrófico y nula contaminación orgánica (Parra et al. 1999, Valdovinos \& Figueroa 2000) y la presencia de población aborigen.

\section{Expresión cartográfica de la síntesis legal}

Como se ha visto, la legislación establece, en algunos casos, franjas de protección a cada lado de cursos de agua y caminos, sin tener en cuenta la estructura o composición de estos espacios. En este trabajo solo se representaron aquellos con bosque nativo y que resultaban protegidos por la ley (Fig. 8). El resto de los espacios que no cumplen con estos requisitos, pero que también forman parte de la base de datos generada, será de utilidad en análisis con objetivos diferentes.

En la Fig. 8 se aprecia que la distribución de los espacios legalmente protegidos sigue aproximadamente el patrón de distribución que presenta el propio bosque nativo y la disposición de los ríos existentes. De esta manera, la legislación ambiental aplicable en el área de estudio, que por definición está orientada a la protección de la vegetación nativa, se refiere más bien a la protección de los recursos hídricos y no a la cubierta vegetal (el bosque nativo) 

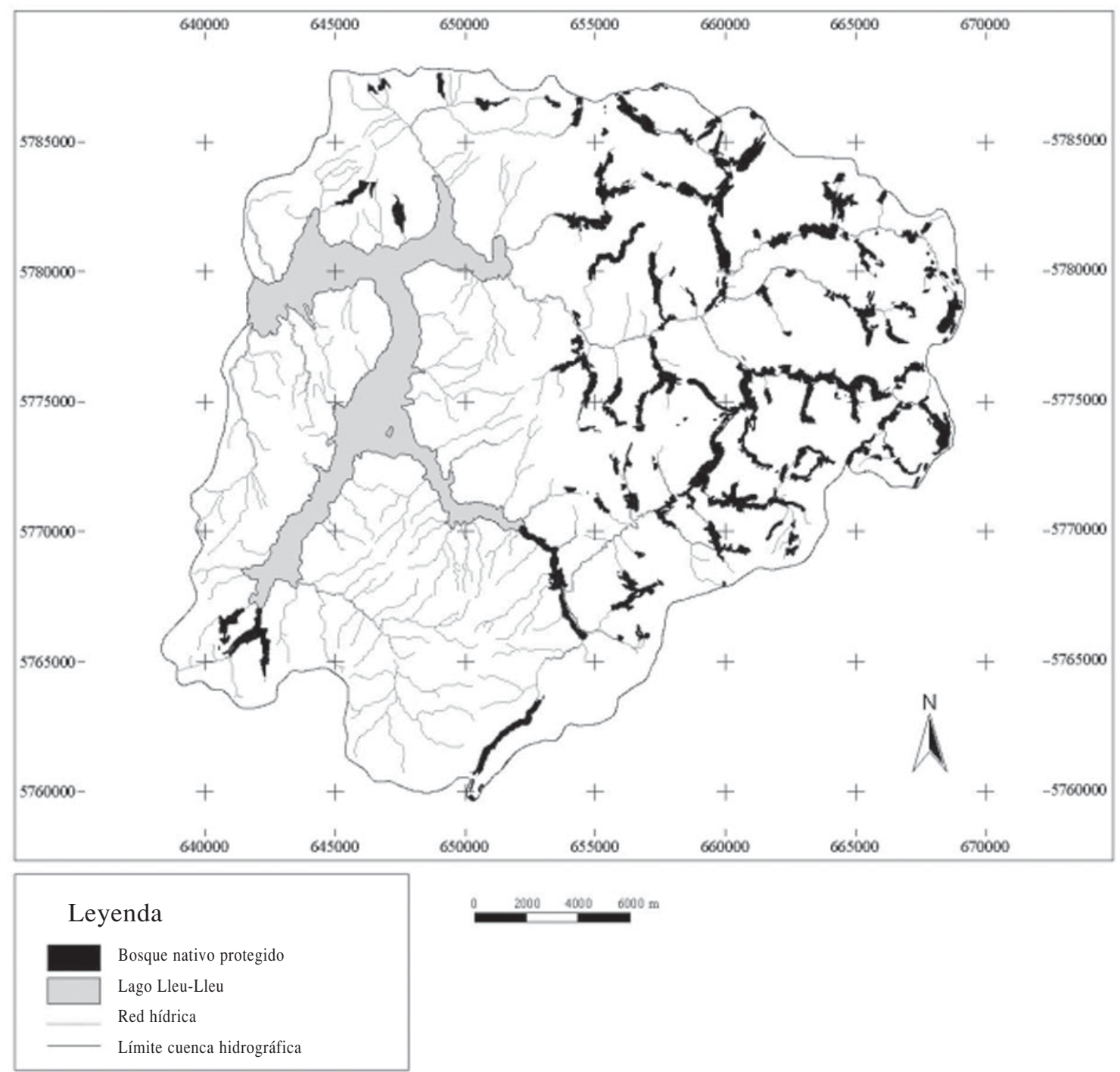

Fig. 8: Expresión cartográfica de síntesis para las leyes analizadas según se aplica en la cuenca del lago Lleu-Lleu (coordenadas UTM).

Synthetic cartographic expression of analyzed laws as they applied to Lleu-Lleu lake basin (UTM coordinates).

propiamente tal. Para evaluar esto último, se puede considerar la distribución actual que presentan los fragmentos de bosque nativo y los ríos, donde se puede observar que existe un alto número de remanentes cuya disposición no está asociada con algún curso de agua (ver Fig. 2 y 8 ), por lo que no es de esperar que la distribución de los fragmentos y ríos tenga alguna relación entre sí dentro de la cuenca.

La Tabla 4 detalla las normas jurídicas y la superficie de bosque nativo que cada una de ellas permite proteger. El total final corresponde a la síntesis cartográfica de todas las leyes aplicadas sobre el área de estudio.
De la Tabla 4 se desprende que la Ley de Bosques permite proteger la mayor superficie del bosque nativo hoy existente en la cuenca del lago Lleu-Lleu (25,8\%); siguiendo en orden de importancia la Ley $\mathrm{N}^{\circ} 18.378(17,5 \%)$. En tanto que resulta paradójico el aporte de las dos normas que están destinadas, especialmente, a la protección de los tipos forestales identificados en el área de estudio. Las normas de manejo confeccionadas por la CONAF para los tipos forestales roble-raulí-coigüe y siempreverde solo protegen en conjunto un $7,3 \%$ del bosque nativo total.

Destaca también la gran diferencia que existe entre las superficies protegidas por cada una 
de las leyes. La diferencia entre los valores máximo y mínimo observada es de 2.148,21 ha.

\section{TABLA 4}

Normas jurídicas aplicables en el área de estudio y superficie de bosque nativo que es protegida como resultado de su aplicación

Legal norms as applied on the study area and area of native forest which is protected as a result of their enforcement

\begin{tabular}{lr}
\hline Norma legal & Superficie (ha) \\
\hline Siempreverde (CONAF 1995) (Fig. 5) & 98,68 \\
Roble-raulí-coigüe (CONAF 1994) (Fig. 4) & 541,90 \\
Ley № 18.378 (Fig. 7) & $1.523,78$ \\
Ley de Bosques (Fig. 6) & $2.246,89$ \\
Total real: todas las leyes eliminando & \\
superposiciones (Fig. 8) & $3.091,67$ \\
\% Bosque nativo & 35,44 \\
\% Cuenca & 5,34 \\
\hline
\end{tabular}

\section{DISCUSIÓN}

Es mandatorio incorporar el concepto de la conservación biológica (en el sentido de Meffe $\&$ Carroll 1994) en la gestión del territorio, especialmente si existe riesgo de que numerosas especies de nuestra biota nativa se extingan, en un horizonte de tiempo cercano, y si el actual Sistema Nacional de Áreas Silvestres Protegidas por el Estado (SNASPE) no se fortalece para cumplir su rol de conservación en forma más eficiente (Armesto et al. 1997). En el sector rural, tradicionalmente bajo disposiciones relacionadas con actividades económicas (Strauss 1996), la legislación orientada a la conservación es dispersa y anacrónica; la biodiversidad no tiene rango legal constitucional como sí ocurre para otros recursos naturales, y la necesidad de interpretar adecuadamente el espíritu de las disposiciones emerge casi en cada ocasión en que se busca su aplicación.

En este estudio hemos utilizado un enfoque de conservación in situ intentando sacar partido de la situación local de expresión de la biodiversidad en su relación con la legislación vigente. Buscando reducir la dimensionalidad compleja de la biodiversidad y la extensa legislación ambiental hemos restringido el estudio al bosque nativo, en una cuenca hidrográfica rural donde concurren usos y conflictos tradicionales en la Octava Región del Bío-Bío. Pauchard et al. (2001) han justificado a la vegetación (y en su caso al bosque) como el mejor indicador de biodiversidad (además fácil de monitorear y por tanto de fiscalizar).

La interpretación de las normas jurídicas ha resultado de primera relevancia para la expresión territorial de la legislación. Los conflictos de interpretación pueden ser de distinta naturaleza: uno de ellos se refiere a la calificación, según la ley, del estatus de cuenca forestal a una determinada cuenca hidrográfica que con esa calificación queda inmediatamente sujeta a restricciones ambientales significativas. Un segundo caso ilustra el libre arbitrio interpretativo en que quedan accidentes geográficos (en nuestro caso, cómo definir un "cerro") cuya definición técnica debería estar clara en el texto legal. Finalmente al declarar monumento natural a la araucaria (Araucaria araucana) es perfectamente argumentable que la protección debe ser entendida para todo el bosque como tipo forestal, es decir, como comunidad, lo que extendería la prohibición de corta a los árboles y otros individuos acompañantes.

Hemos demostrado que aunque no toda la legislación puede ser cartografiada con claridad, ello sí es posible para las disposiciones seleccionadas. Se ha puesto particular interés en la legislación destinada a proteger el bosque nativo, ya que al tener ese objetivo debiera ser claramente aplicable. En la práctica, esto es lo que permite definir las sanciones legales y facilita las resoluciones judiciales, que no siempre han sido bien aceptadas en cuanto a su efectividad.

Con ello, también estamos definiendo un “mínimo legal" al dar respuesta a la pregunta ¿cuánto territorio protege efectivamente la legislación vigente? La superficie debiera incrementarse al incorporar otras disposiciones ambientales a la cartografía. Y si una determinada disposición no puede expresarse cartográficamente (esto es, en términos de superficie territorial a la que afecta o se aplica), entonces, a nuestro entender, claramente hay algún tipo de problema con su aplicabilidad. De ahí que la aproximación que aquí se propone adquiera el valor de una verdadera "puesta a prueba", tanto de la efectividad real de una disposición legal como, también, de que ella no es solo una manifestación de buenas intenciones.

En la cuenca del lago Lleu-Lleu la protección del bosque nativo es un eufemismo, ya que las disposiciones legales aseguran las vías que 
permiten eliminar físicamente o por reemplazo al bosque nativo. Además, las normas estándar de CONAF se orientan a la protección hídrica, asegurando difícilmente la conservación de la diversidad biológica. Esto ocurre aun a pesar que han sido formulados para reemplazar, en forma optativa, los tradicionales planes de manejo y, en consecuencia, asegurar la preservación, conservación, mejoramiento y acrecentamiento de los recursos naturales renovables y su ecosistema ${ }^{28}$. Por último, claramente solo son aplicables en la actualidad, donde existen fragmentos de bosque nativo.

A pesar de ello, también hemos demostrado que la cartografía de disposiciones relacionadas con la protección hídrica permite articular una red de corredores para interconectar remanentes, lo cual puede representar una clara opción de sobrevivencia para poblaciones de plantas y animales que los usen efectivamente. La eficiencia del diseño así como la estructura (número de estratos, relaciones núcleo-borde, composición) son materias que pueden ser estudiadas en cada caso con el fin de desarrollar soluciones óptimas. Materia aparte constituye el que la tipología para el bosque, incorporada en la legislación, no permite la distinción de las numerosas variantes estructurales y de composición que se encuentran en el territorio.

La Ley de Bosques ${ }^{29}$, a diferencia del resto de las normas jurídicas, permite, según nuestros resultados, la protección de un sector territorialmente aún mayor. Esto tiene especial relevancia desde la perspectiva de conservación, ya que existe controversia respecto de su vigencia futura. Algunos autores plantean que es necesaria su derogación, aludiendo a que el artículo $5^{\mathrm{o}}$ y los reglamentos orientados a especies determinadas "han quedado obsoletas a la luz de los modernos tipos forestales definidos en el Reglamento Técnico del Decreto Ley 701" (Gallardo 1985, Gallardo 1989). En cambio, otros, reconocen su directa relación con el manejo de cuencas, donde posibilita la protección del suelo y el agua utilizando prohibiciones sobre la vegetación (Ortiz 1986).

Por otro lado, la legislación también ofrece opciones que pueden ser vistas como una posibilidad concreta para modificar las relaciones en el espacio y asegurar la conservación de biodiver-

${ }^{28}$ Artículo $2^{\circ}$, Título Preliminar, Decreto Ley $N^{\circ} 701$, Diario Oficial de Chile, 28 de octubre de 1974.

${ }^{29}$ Ley $\mathrm{N}^{\circ} 4.363$, Diario Oficial de Chile, 31 de julio de 1931. sidad, por ejemplo, cuando señala que se puede reforestar en un sitio distinto al explotado ${ }^{30}$. En efecto, los propietarios que poseen bosque nativo y deseen transformar sus tierras en cultivos agrícolas, podrían efectuar la reforestación obligatoria en un terreno donde se haya diseñado un corredor ribereño y no existe la cubierta vegetal apropiada, o en sectores donde pudiera ampliarse un fragmento para unirlo a otro cercano, por ejemplo en las áreas "islas" no conectadas directamente a los corredores basados en la red hídrica. Igual consideración puede realizarse respecto de los otros caminos legales que permiten la eliminación total del bosque nativo.

En áreas como la cuenca del lago Lleu-Lleu, donde el Estado compromete inversiones de carácter social como el fomento del turismo o el apoyo a comunidades indígenas (como indica el plan seccional ya aprobado, Durán \& Martínez 2000), la aproximación aquí ilustrada constituye una buena herramienta para planificar y monitorear, condicionando la entrega de fondos sociales, por ejemplo, a que se dé cumplimiento a la ley en cuanto a la protección hídrica que se desprende de la legislación forestal o en seguimientos a la entrega de subsidios cuando se implementan franjas de reforestación para la protección de cursos de agua, los cuales, automáticamente, funcionarán como corredores biológicos que aseguran las migraciones locales $\mathrm{y}$ el intercambio entre fragmentos.

Emerge, entonces, un campo fértil para el deslinde de responsabilidades, identificando a la autoridad a quien corresponde hacer cumplir la ley, la valoración económica de la restauración o la efectividad de las políticas de subsidio para la conservación. Los sistemas de información geográfica como el aquí empleado aparecen como herramientas poderosas para el apoyo de todas esas acciones.

\section{AGRADECIMIENTOS}

Esta investigación es parte de la Tesis de Doctorado en Ciencias Ambientales de Patricio Pellet. Agradecemos financiamiento a Proyecto FONDECYT 196-0600; al Sr. Bolívar Ruiz (Director Regional de CONAMA VIII Región) la asesoría y revisión de materias legales.

\footnotetext{
${ }_{30}$ Artículo $22^{\circ}$, D. L. N ${ }^{\circ}$ 701, Diario Oficial de Chile, 28 de octubre de 1974 .
} 


\section{LITERATURA CITADA}

ARMESTO J, C VILLAGRÁN \& MK ARROYO (eds) (1997) Ecología de los bosques nativos de Chile. Editorial Universitaria, Santiago, Chile. 477 pp.

CASTILLO M (1994) Régimen jurídico de protección del medio ambiente. Aspectos generales y penales. Segunda edición. Ediciones Bloc, Santiago, Chile. $329 \mathrm{pp}$.

CONAF (1994) Manual de procedimientos para normas de manejo aplicables a faenas de raleo en tipo forestal de RO-RA-CO. Gerencia Técnica, Departamento Control Forestal, Santiago, Chile. 35 pp.

CONAF (1995) Manual de procedimientos para evaluación de solicitudes normas de manejo aplicables a corta final tipo forestal siempreverde. Gerencia Técnica, Departamento Control Forestal, Santiago, Chile. 53 pp.

CONAF-CONAMA (1998) Proyecto catastro y evaluación de los recursos vegetacionales nativos. Sistema y Base de Datos versión 2.0cli. Aplicación Arc View en CD.

CONAF-CONAMA (1999a) Catastro y evaluación de recursos vegetacionales nativos de Chile. Informe Regional Octava Región, Concepción, Chile. 130 pp.

CONAF-CONAMA (1999b) Catastro y evaluación de recursos vegetacionales nativos de Chile. Informe Nacional con Variables Ambientales, Santiago, Chile. 89 pp.

CONAMA (1992) Repertorio de la legislación de relevancia ambiental vigente en Chile. Santiago, Chile. 846 pp.

CONAMA (1993) Repertorio de la legislación de relevancia ambiental vigente en Chile. Suplemento Número 1. Santiago, Chile. 443 pp.

DURÁN M \& W MARTÍNEZ (2000) Seccional del lago Lleu-Lleu. Extracto del resumen ejecutivo del estudio. Revista Urbano (Chile) 3: 82-95.

FLORES L (1997) Marco jurídico aplicable a las áreas silvestres protegidas. Informe Corporación Nacional Forestal, Santiago, Chile. 33 pp.

GALLARDO E (1985) Legislación sobre protección de la flora arbórea y arbustiva nativa chilena. En: Benoit IL (ed) Libro rojo de la flora terrestre de Chile (Primera Parte). Corporación Nacional Forestal, Santiago, Chile. 157 pp.

GALLARDO E (1989) Marco jurídico del bosque nativo y su manejo. Exposición efectuada en las jornadas sobre el bosque nativo y su manejo durante el 17 y 18 de noviembre en Concepción. Concepción, Chile. $14 \mathrm{pp}$.

HUSCH B (1994) La solución es mejorar el control, no prohibir el uso del bosque. Ambiente y Desarrollo (Chile) 10: 33-35.

JORDAN C (1995) Conservation. John Wiley \& Sons, Inc., New York, New York, USA. 340 pp.

KING C (1993) La expresión territorial planimétrica de la legislación ambiental: Ley de Bosques y Reglamento del Decreto Ley 701. Seminario de Título para optar al Diplomado en Análisis y Gestión del Ambiente, Escuela de Graduados Universidad de Concepción, Concepción, Chile. 60 pp.
MARDONES M (1999) Contribución al conocimiento geomorfológico de las cuencas hidrográficas de los lagos Lanalhue y Lleu-Lleu. Revista Geográfica de Chile Terra Australis 44: 87-106.

MEFFE K \& R CARROLL (1994) Principles of conservation biology. Sinauer Associates, Inc., Sunderland, Massachusetts, USA. 601 pp.

MOPT (1995) Estrategia nacional para la conservación y el uso sostenible de la diversidad biológica. Madrid, España. 67 pp.

ORMAZÁBAL C (1993) The conservation of biodiversity in Chile. Revista Chilena de Historia Natural 66: 383-402.

ORTIZ S (1986) Legislación vigente en el ámbito del manejo de cuencas hidrográficas. Corporación Nacional Forestal Octava Región, Concepción, Chile. 35 pp.

PARRA O, S BASUALTO, R URRUTIA \& C VALDOVINOS (1999) Estudio comparativo de la diversidad fitoplanctónica de cinco lagos de diferentes niveles de eutroficación del área litoral de la región del Bío-Bío (Chile). Gayana Botánica (Chile) $56: 93-108$

PAUCHARD A, E UGARTE \& J MILLÁN (2001) Biodiversidad y vegetación en la línea de base para la evaluación del impacto ambiental de proyectos de inversión en áreas silvestres protegidas de Chile. En: Alveal K (ed) Sustentabilidad de la biodiversidad. Un problema actual, bases científico técnicas, teorizaciones y proyecciones: 757-773. Ediciones Universidad de Concepción, Concepción, Chile.

PICKETT STA \& JN THOMPSON (1978) Patch dynamics and the design of nature reserves. Biological Conservation 13: 27-37.

QUIROGA R \& S VAN HAUWERMEIREN (1996) Globalización e insustentabilidad: Una mirada desde la economía ecológica. Instituto de Ecología Política, Programa de Economía Ecológica, Santiago, Chile. 199 pp.

SIMONETTI J \& J ARMESTO (1991) Conservation of temperate ecosystems in Chile: course versus finefilter approaches. Revista Chilena de Historia Natural 64: 615-626.

SOULE ME (ed) (1987) Viable populations for conservation. Cambridge University Press, New York, New York, USA. 206 pp.

STRAUSS C (1996) Ordenamiento territorial sustentable: los límites de lo imposible en Chile. Documento de Trabajo, versión preliminar, Santiago, Chile. 57 pp.

UICN (1980) Estrategia mundial para la conservación. Segunda edición. Gland, Suiza. 150 pp.

VALDOVINOS C \& R FIGUEROA (2000) Benthic community metabolism and tropic conditions of four South American lakes. Hydrobiologia 429: 151-156.

VALENZUELA R (1994) Diagnóstico preliminar del ordenamiento jurídico vigente, en lo que se refiere a la protección de la diversidad biológica. Contrato № 01-0007-001 preparado para la Comisión Nacional del Medio Ambiente, Santiago, Chile. 47 pp. 